\title{
Sobre 0 uso dos termos geocronológicos e cronoestratigráficos
}

\author{
ON THE USAGE OF GEOCHRONOLOGIC AND CRONOSTRATIGRAPHIC TERMS
}

\author{
Mitsuru Aral ${ }^{1}$, Pércio de Moraes Branco ${ }^{2}$ \\ 1 UNESP/IGCE/UNESPetro. Rio Claro-SP, Brasil. E-mall: mitsuru.aral@gmall.com \\ 2 Geólogo, autor do Guia de Redação para a Área de Geociências (Branco 2014). E-mall: Perclomb@gimall.com
}

\begin{abstract}
This paper aims to reinforce and promote rules for the correct and unambiguous usage of geochronologic and chronostratigraphic terms in the Brazilian geoscientific literature. The distinction between the two types of terms was clearly established by the Brazilian Stratigraphic Nomenclature Guide in 1986. However, we have often observed the misuse of these terms; in particular, chronostratigraphic terms used in place of geochronological terms, and vice versa. In the early 1990s, the first author began a campaign against such misuse through personal contacts and the publication of short notes focusing on the problem. The decision to write this longer and more comprehensive article has been motivated by the first author's role as a member of the editorial committees of Petrobras's Bulletin of Geosciences (2006-2013) and the Brazilian Journal of Paleontology (since 2016), thereby alerting

him to the seriousness of the problem.
\end{abstract}

\begin{abstract}
Manuscrito:
Recebido: 23/fev/18

Corrigido: $11 /$ jun/18

Aceito: $13 / \mathrm{jul} / 18$

Citation: Arai M., Branco P.M. 2018. Sobre 0 uso dos termos geocronológicos e cronoestratigráficos. Terræ Didatica, 14(3):217-224. URL: http://www. ige.unicamp.br/terraedidatica/.
\end{abstract}

Keywords: Stratigraphic nomenclature, geoscientific literature, writing standard.

\section{Introdução}

Ao longo das últimas décadas, o primeiro autor deste trabalho vem fazendo campanha pelo uso correto dos termos geocronológicos e cronoestratigráficos (Fig. 1), pois existe na comunidade científica uma carência na percepção da diferença entre esses termos. Há quem não leve a sério essa questão, mas existe o Guia de Nomenclatura Estratigráfica Brasileira (Petri et al. 1986) que deve ser seguido. Boa parte do tema abordado neste artigo já foi publicada em forma de uma série de pequenos artigos no Boletim da Sociedade Brasileira de Paleontologia - Núcleo RJ/ES (Arai 1993a, b, 1994). O assunto é relançado aqui, pois a série não produziu discussões em nível esperado (talvez a tiragem do Boletim da SBP fosse pequena demais para o público que deveria ser atingido). Para isso, tornou-se mister a participação do segundo autor, conhecido pelas obras de orientação na redação geocientífica (e.g. Branco 2014).

O presente trabalho se justifica pelo anseio da comunidade científica para a solução desta questão que, há muito tempo, aflige muitos geocientistas, principalmente estratígrafos e paleontólogos (Fig. 2). A percepção deste problema ampliou-se significativamente pela experiência do primeiro autor como integrante dos corpos editoriais dos periódicos Boletim de Geociências da Petrobras (2006-2013) e Revista Brasileira de Paleontologia (desde 2016). Essa experiência revelou que tanto revisores como editores se ressentem da falta de uma norma clara e bem estabelecida. A mesma problemática foi detectada entre os membros da Comissão Brasileira de Sítios Geológicos e Paleontológicos (SIGEP). O problema não é exclusivo do Brasil, conforme o observado por Loon (2013, p. 3): "A study of the literature leads to the conclusion that few authors - and apparently far too few editors - are aware of the differences between chronostratigraphic and geochronological nomenclature".

A versão aqui apresentada sofreu modificações profundas em função do Acordo Ortográfico da Língua Portuguesa (e.g. ABL 2009, MEC 1990, Silva 2017, Tufano 2008).

\section{Descrição da problemática}

Basicamente existem dois problemas. O primeiro é a grafia dos termos geocronológicos informais, e o segundo é o uso adequadamente distinto dos termos geocronológicos em relação aos cronoestratigráficos. 


\begin{tabular}{|c|c|c|c|}
\hline \multicolumn{2}{|c|}{ TERMOS } & \multicolumn{2}{c|}{ TERMOS } \\
CRONOESTRATIGRÁFICOS & \multicolumn{2}{c|}{ GEOCRONOLÓGICOS } \\
\hline & Exemplo & & Exemplo \\
\hline Eonotema & Fanerozoico & Éon & Fanerozoico \\
\hline Eratema & Mesozoico & Era & Mesozoico(a) \\
\hline Sistema & Cretáceo & Período & Cretáceo \\
\hline Série & Cretáceo Inferior & Época & Eocretáceo \\
\hline Andar & Aptiano & Idade & Aptiano \\
\hline Subandar & Aptiano superior & Subidade & Neoaptiano \\
\hline
\end{tabular}

Figura 1. Comparação entre os termos cronoestratigráficos e geocronológicos com respectivos exemplos em hierarquias correspondentes. (*) OBS.: Na opinião de ICS (2017), "subandar" e "subidade" constituem hierarquias informais.

\subsection{0 primeiro problema: grafia dos termos geocronológicos informais}

O primeiro problema é tanto quanto inócuo, mas incomoda os que almejam escrever textos rigorosamente dentro da regra. Esse problema não existe para termos cronoestratigráficos, já que a criação de seus termos informais se dá através de adjetivos, como por exemplo, Albiano inferior. Observe-se que o termo Albiano, que é formal, é grafado em maiúscula, e o adjetivo inferior, que lhe confere sua subdivisão informal, em minúscula. Por outro lado, o Cretáceo Inferior é grafado assim mesmo (com Inferior em maiúscula), pois o termo é formal com hierarquia de série, e não uma mera subdivisão de uma unidade formal. Quanto aos termos cronoestratigráficos, há este consenso até mesmo em nível internacional. Nos países de língua inglesa, por exemplo, escreve-se Lower Cretaceous e lower Albian (Owen 1987, 2009).

Para averiguar se um determinado termo é formal ou não, basta consultar a Carta Cronoestratigráfica Internacional (CCI) que é atualizada periodicamente. A versão mais recente consultada é a v. 2017/02 (ICS 2017). De modo geral, todas as subdivisões de andar/idade são informais, já que a CCI não apresenta nenhuma categoria abaixo de andar/ idade. Há casos em que ocorrem subdivisões informais em nível de série/época; p. ex. "Cretáceo médio" - repare que, na CCI, o Sistema/Período Cretáceo é bipartite, tendo apenas as séries formais Cretáceo Inferior (Lower Cretaceous) e Cretáceo Superior (Upper Cretaceous) e épocas formais Eocretáceo (Early Cretaceous) e Neocretáceo (Late Cretaceous). Segundo a CCI, as subdivisões das séries/épocas do
Cenozoico não são formais. Assim, os termos como "Eoceno médio" e "Mioceno superior" deveriam ser considerados como informais, apesar da existência de especialistas que defendem sua formalização (e.g. Head et al. 2017). Igualmente polêmico é o fato de o Terciário, um termo tradicional, não constar na CCI. Alguns autores até sugeriram a manutenção formal do Sistema/Período Terciário, transferindo os termos Paleógeno e Neógeno para a categoria de subsistema/ subperíodo (e.g. Head et al. 2008).

Quanto à nomenclatura dos termos geocronológicos, a regra não é tão simples, sobretudo em se tratando da Nomenclatura Estratigráfica Brasileira (Petri et al. 1986) que preferiu o uso dos prefixos EO-, MESO- e NEO- para as subdivisões (o povo da língua inglesa não sofre com isso, já que usa adjetivos também para termos geocronológicos. Ex.: Early Cretaceous e early Albian). A primeira dúvida que surgiu em decorrência do uso desses prefixos é quanto ao uso do hífen. Seguindo à risca o Acordo Ortográfico da Língua Portuguesa (e.g. ABL 2009, MEC 1990, Silva 2017, Tufano 2008), podemos estabelecer as seguintes regras:

a) se os termos que se seguem aos prefixos EO, MESO e NEO tiverem "O" como letra inicial, usa-se hífen. Ex.: EO-OLIGOCENO.

b) se os termos que se seguem tiverem vogais diferentes de "O", não se usa o hífen. Ex.: MESOEOCENO, NEOAPTIANO, EOALBIANO, etc..

c) se os termos que se seguem tiverem consoantes diferentes de "H", "R" e "S", justapõem-se os termos aos prefixos, não se usando o hífen. Ex.: EOMIOCENO, NEOCAMPANIANO, MESOTURONIANO, etc..

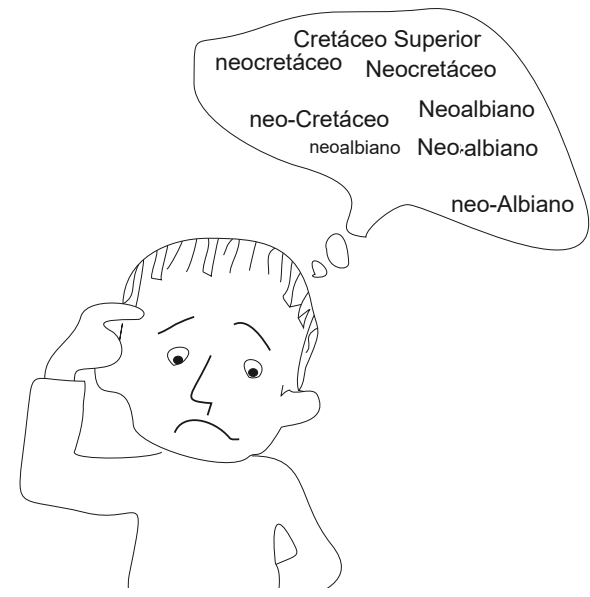

Figura 2. A escolha de termo adequado nem sempre é tarefa fácil 
d) se os termos forem iniciados pelas letras "R" ou "S", efetua-se a duplicação das mesmas. Ex.: EOSSANTONIANO, NEORRUPELIANO, etc..

b) o prefixo sempre é seguido de hífen, quando precede palavra iniciada pela letra "H". Ex.: NEO-HAUTERIVIANO.

Resolvido o problema de hifenização, resta ainda decifrar a questão do uso de maiúscula/ minúscula. Alguns autores (e.g. Beurlen et al. 1992) têm optado pela utilização ostensiva de minúscula nos termos geocronológicos informais (p. ex., mesocenomaniano, neoturoniano, eocampaniano). Rios-Netto \& Koutsoukos (1994b) também defenderam que os termos informais sejam grafados em minúscula, alegando que a nova palavra formada com o uso daqueles prefixos ganha autonomia semântica em relação a sua base. Folha de S. Paulo (1992) tem a mesma opinião, afirmando que palavras separadas por hífen mantêm sua autonomia fonética. Assim, o uso de maiúscula/minúscula deve incidir sobre todos os elementos das palavras hifenadas, com exceção das partículas átonas que sempre permanecem com minúscula. Por outro lado, estes autores lembraram, com propriedade, que, "caso essa regra ortográfica seja seguida, ipsis literis, para a terminologia das unidades geocronológicas, poderá gerar confusão quanto ao caráter formal ou informal do intervalo representado pela palavra-base. Por exemplo, em um texto como o seguinte: 'do neossantoniano ao eocampaniano', fica mascarado o caráter formal do Santoniano e do Campaniano em seu todo, e não somente as subdivisões destes".

Para esquivar desse problema, Arai (1994) chegou mesmo a propor o uso sistemático do hífen, separando os prefixos em minúscula dos termos geocronológicos em maiúscula (ex.: eo-Albiano, eo-Santoniano, eo-Oligoceno, etc.). Isso seria uma solução prática, mas violaria as normas oficiais de uso do hífen, e, portanto, deve ser rejeitado.

O uso de inicial minúscula mascara o caráter formal da unidade prefixada e isso, na nossa opinião, é pior do que dar a impressão de ser formal um termo que não o é. Algumas analogias mostram que se deve usar maiúscula:

- a porção do continente de Gondwana correspondente à atual África poderia ser chamada de Protoáfrica ou Paleoáfrica, mas ficaria estranho usar protoáfrica ou paleoáfrica;
- quando o Brasil for um país moderno e plenamente inserido no contexto das nações desenvolvidas (não custa sonhar...), poderá receber o título de Neobrasil, mas não neobrasil;

- se o Flamengo montar uma equipe imbatível, seus torcedores poderão chamá-lo de Superflamengo, mas nunca de superflamengo.

Essas analogias não são perfeitas, mas nos oferecem uma melhor visualização do problema.

Além disso, a utilização ostensiva de minúscula não está compatível com o Formulário Ortográfico, aprovado pela Academia Brasileira de Letras na sessão de 12.08.1943, que prega o uso de maiúscula "nos nomes próprios de eras históricas e épocas notáveis". Branco (2014, p. 135) foi bem claro ao defender o emprego da maiúscula nos nomes de épocas, eras e períodos geológicos. A nosso ver, o uso de maiúscula em termos geocronológicos é um procedimento que, em atendimento às normas vigentes da língua portuguesa, deve ser seguido à risca. Portanto, todos os termos geocronológicos, sejam eles formais ou não, devem ser grafados com inicial maiúscula.

Ainda na questão do uso de maiúscula/minúscula, convém lembrar que toda esta discussão se refere aos termos geocronológicos propriamente ditos, que são nomes próprios (substantivos). Os adjetivos devem ser sistematicamente grafados em minúscula, sejam originários de termos formais ou não. Ex.: flora mesozoica ( = flora do Mesozoico), vulcanismo eocretáceo (= vulcanismo do Eocretáceo), fauna neoalbiana (= fauna do Neoalbiano), sedimento mesoturoniano (= sedimento do Turoniano médio), etc.. Cabe salientar que essas peculiaridades variam de língua para língua. Em inglês, por exemplo, os adjetivos derivados de nomes próprios são grafados em maiúscula (ex.: the Brazilian coast, the Cretaceous life, the American railways, etc.).

Como solução ideal para toda a problemática envolvida no uso de termos geocronológicos informais, nós recomendamos a utilização mais frequente dos adjetivos pospostos, cuja prática, além de ser observada em outros países da língua latina (Fig.3; Hedberg 1979, p.99, 1980, p.76), está prevista no Guia de Nomenclatura Estratigráfica (Petri et al. 1986, p.393). Os autores desse guia sugeriram o uso dos adjetivos ANTIGO, INTERMEDIÁRIO e TARDIO, correspondentes, respectivamente, aos prefixos Eo-, Meso- e Neo-. Por outro lado, Beurlen et al. (1992) utilizaram um repertório maior de adjetivos (INICIAL, ANTIGO, MÉDIO, NOVO, TARDIO e TERMINAL), muitas vezes em combinação com os termos geocronológicos informais 
dotados de prefixos, procurando, assim, evitar termos mais confusos como Eoneocampaniano (= parte antiga do Neocampaniano ou parte inicial do Campaniano tardio) e Eo-Oligoceno (= parte antiga do Oligoceno; não confundir com a expressão Eo-Oligoceno que se relaciona ao intervalo EocenoOligoceno). Para esses autores os termos INICIAL e TERMINAL não são meros sinônimos dos adjetivos ANTIGO e TARDIO, significando, respectivamente, as partes mais antiga e mais nova, em uso análogo aos termos ingleses informais earliest $\mathrm{e}$ latest (ex.: Cretáceo inicial = earliest Cretaceous). Já Rios-Netto \& Koutsoukos (1994a) propuseram o uso dos adjetivos INICIAL, MÉDIO e TARDIO como alternativa ao uso dos prefixos Eo-, Meso- e Neo-, enquanto que Carvalho (2004) propôs os adjetivos INICIAL, MÉDIO e FINAL para o mesmo fim.

A nossa proposta é que sejam amplamente utilizados os adjetivos ANTIGO, MÉDIO e NOVO, em substituição aos prefixos Eo-, Meso- e Neo(Fig. 3).

A utilização do adjetivo INTERMEDIÁRIO é inócua, já que o termo MÉDIO pode ser empregado tanto no sentido cronológico, como no topológico. O termo TARDIO não é adequado na língua portuguesa por denotar extemporaneidade. Ainda, há o termo DERRADEIRO, sugerido pessoalmente pela Dra. Maria Helena Hessel, mas a nosso ver ele equivaleria mais ao termo TERMINAL.

\subsection{0 segundo problema: termo geocronológico $\mathrm{x}$ termo cronoestratigráfico}

Dada a problemática que envolve o uso de termos geocronológicos, a nossa recomendação é usar termos cronoestratigráficos sempre que for possível. Aliás, um dos problemas sérios que se observam frequentemente é o uso indevido de termos geocronológicos no lugar de termos cronoestratigráficos, e vice-versa. A questão é basicamente semântica. Primordialmente, há que se entender que o termo geocronológico designa o tempo geológico (entidade abstrata) e que o termo cronoestratigráfico se refere à rocha (entidade física) que representa o tempo.

A seguir apresentaremos alguns exemplos para clarificar esta ideia:

1a) Aquele dinossauro viveu no Eocretáceo. correto

1b) Aquele dinossauro viveu no Cretáceo Inferior. - errado (Fig. 4)

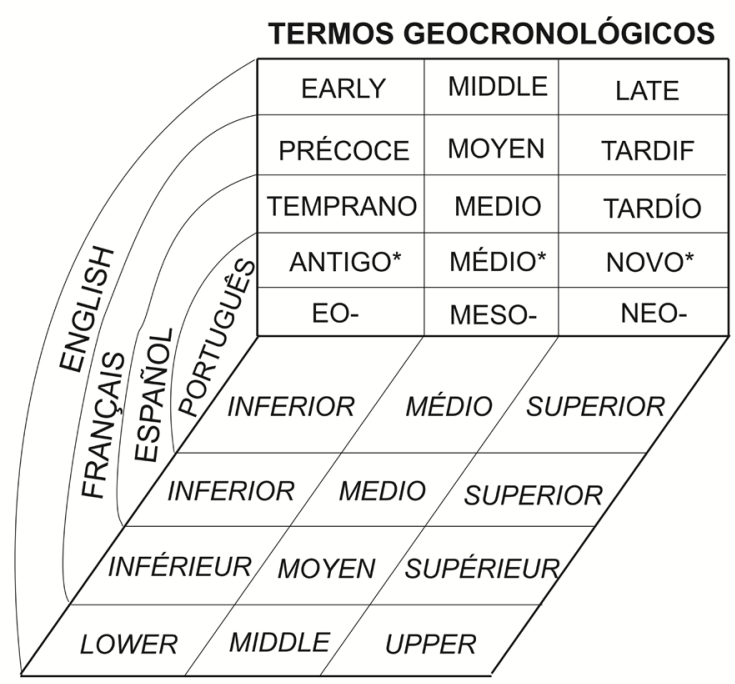

TERMOS CRONOESTRATIGRÁFICOS

Figura 3. Comparação dos adjetivos associados aos termos geocronológicos e cronoestratigráficos nas línguas portuguesa (Brasil), inglesa, francesa e espanhola

2a) Este fóssil provém do Neocretáceo. - errado

2b) Este fóssil provém do Cretáceo Superior. correto

3a) O topo do Neojurássico está a $500 \mathrm{~m}$ de profundidade. - errado

3b) O topo do Jurássico Superior está a $500 \mathrm{~m}$ de profundidade. - correto

4a) Microfósseis da Formação Santana (Eocretáceo do Nordeste...) - errado

4b) Microfósseis da Formação Santana (Cretáceo Inferior do Nordeste...) - correto

5a) Mapa paleogeográfico do Neojurássico - correto

5b) Mapa paleogeográfico do Jurássico Superior - errado

6a) Contato entre o Triássico Superior e o Jurássico Inferior - correto

6b) Contato entre o Neotriássico e o Eojurássico - errado

7a) Nos primórdios do Eo-Ordoviciano... - correto

7b) Nos primórdios do Ordoviciano Inferior... errado

A mesma preocupação deve ser estendida para casos que mostram empilhamentos estratigráficos. Se a escala vertical for espessura ou profundidade, os termos associados devem ser obrigatoriamente 
cronoestratigráficos; e, se for escala em tempo geológico, devem ser geocronológicos (Fig. 5).

Devido ao desconhecimento dos editores, muitos periódicos acabam publicando artigos contendo esse tipo de erro. No entanto, alguns periódicos recomendam explicitamente que os autores sigam à risca o uso adequado de termos cronoestratigráficos e geocronológicos. O exemplo mais louvável é da Cretaceous Research que traz instruções relativas a essa problemática (Elsevier, 2017).

\section{Divergência entre o português lusitano e 0 português brasileiro}

O Acordo Ortográfico da Língua Portuguesa (e.g. ABL 2009, MEC 1990) não interferiu na divergência existente entre as terminologias usadas em Portugal e no Brasil. A consulta à Tabela Cronoestratigráfica Internacional (ICS 2013) revela o caráter oficial dessa divergência. Os termos que mais divergem são relativos a sistemas/períodos. Por exemplo, enquanto no Brasil se usam Cambriano, Ordoviciano, Siluriano, Devoniano, Carbonífero, Permiano, Triássico, Jurássico, Cretáceo, Paleógeno, Neógeno, etc., em Portugal, se usam respectivamente Câmbrico, Ordovícico, Silúrico, Devónico, Carbónico, Pérmico, Triássico, Jurássico, Cretácico, Paleogénico, Neogénico, etc. Neste aspecto, o português lusitano se aproxima mais do espanhol (Fig. 6).

\section{Considerações finais}

Tudo que foi apresentado aqui deve ser discutido num fórum com a maior participação possível de geocientistas e, se possível, também de gramáticos e filólogos. Apesar da recomendação do Guia de Nomenclatura Estratigráfica Brasileira (Petri et al. 1986), não há consenso unânime quanto ao uso do adjetivo. Muitos não gostam dos adjetivos antigo e novo e preferem usar os adjetivos precoce e tardio, respectivamente com os sentidos equivalentes aos termos early e late.

Convém lembrar também que algumas comunidades geológicas simplesmente ignoram a existência da nomenclatura geocronológica (talvez por acharem complicada demais). É o caso, por exemplo, dos alemães, dos portugueses e da maioria dos franceses, que usam os adjetivos superior e inferior também com a conotação geocronológica. $\mathrm{Na}$ Argentina, existe uma tendência inversa: muitos especialistas argentinos usam os adjetivos temprano

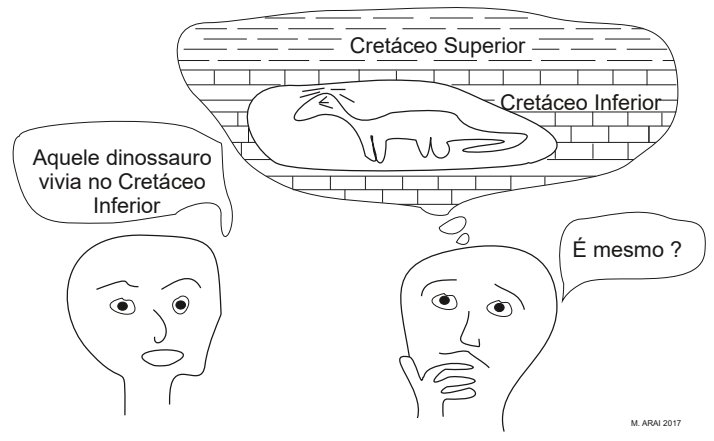

Figura 4. Exemplo de uso inadequado de um termo que pode levar a uma interpretação equivocada

e tardío nos lugares que caberiam melhor os adjetivos inferior e superior (e.g. Barreda \& Palamarczuk 2000, Di Pasquo 2003, Quattrocchio et al. 2003). Há também trabalhos de nomenclatura estratigráfica que simplesmente ignoram a existência de termos geocronológicos (e.g. Kumpulainen 2017).

Há também o caso do Pré-Cambriano em que os prefixos Paleo-, Meso- e Neo- são aplicados indistintamente para os termos cronoestratigráficos e geocronológicos (ICS 2017) - e.g. Paleoproterozoico, Mesoproterozoico e Neoproterozoico. O mesmo acontece com os termos paleoantropológicos aplicados à Idade da Pedra (Paleolítico, Mesolítico e Neolítico). Além disso, é comum observar a atribuição dos adjetivos inferior, médio e superior ao termo Paleolítico no sentido de divisão de tempo (e.g. Wikipedia 2017). Convém também observar que é muito comum a atribuição equivocada do termo "período" para essas divisões (e.g. Busca Escolar 2015).

Do ponto de vista semântico, o uso disciplinado

\begin{tabular}{|c|c|c|c|c|c|}
\hline Série & Formação & Espessura & \multirow{2}{*}{$66 \mathrm{Ma}^{-}$} & Época & Formação \\
\hline \multirow{2}{*}{$\begin{array}{l}\text { Cretáceo } \\
\text { Superior }\end{array}$} & $\begin{array}{l}\text { Formação } \\
\text { Obscura }\end{array}$ & $250 \mathrm{~m}$ & & Neocretáceo & $\begin{array}{c}\text { Formação } \\
\text { Obscura } \\
\begin{array}{c}\text { Formação } \\
\text { Perfecta }\end{array}\end{array}$ \\
\hline & $\begin{array}{c}\text { Formação } \\
\text { Perfecta } \\
\text { discordância }\end{array}$ & $170 \mathrm{~m}$ & $100 \mathrm{Ma}$ & Eocretáceo & hiato \\
\hline Jurássico & Formação & \multirow{2}{*}{$350 \mathrm{~m}$} & \multirow{2}{*}{$145 \mathrm{Ma}$} & & \\
\hline Superior & Horrorosa & & & Neojurássico & $\begin{array}{l}\text { Formação } \\
\text { Horrorosa }\end{array}$ \\
\hline
\end{tabular}

Figura 5. Quadro estratigráfico de uma área fictícia, mostrado em modo cronoestratigráfico (esquerda) e em modo geocronológico (direita). Figura inspirada na Text-figure 1 de Owen (2009, p. 113) 


\begin{tabular}{|c|c|c|c|c|c|c|}
\hline LÍNGUAS & $\underset{\text { Éon }}{\text { Eonotema/ }}$ & $\begin{array}{c}\text { Eratema/ } \\
\text { Era }\end{array}$ & $\begin{array}{l}\text { Sistema/ } \\
\text { Período }\end{array}$ & $\begin{array}{l}\text { Série/ } \\
\text { Época }\end{array}$ & $\begin{array}{l}\text { Andar/ } \\
\text { Idade }\end{array}$ & $\begin{array}{l}\text { Subandar/ } \\
\text { Subidade }\end{array}$ \\
\hline ENGLISH & Phanerozoic & Paleozoic & Devonian & $\begin{array}{l}\text { Upper Devonian/ } \\
\text { Late Devonian }\end{array}$ & Famennian & $\begin{array}{l}\text { lower Famennian/ } \\
\text { early Famennian }\end{array}$ \\
\hline FRANÇAIS & Phanérozoïque & Paléozoïque & Dévonien & $\begin{array}{l}\text { Dévonien Supérieur/ } \\
\text { Dévonien Tardif }\end{array}$ & Famennien & $\begin{array}{l}\text { Famennien inférieur/ } \\
\text { Famennien précoce }\end{array}$ \\
\hline $\begin{array}{l}\text { ESPAÑOL } \\
\text { (ESPAÑA) }\end{array}$ & Fanerozoico & Paleozoico & Devónico & $\begin{array}{l}\text { Devónico Superior/ } \\
\text { Devónico Tardío }\end{array}$ & Fameniense & $\begin{array}{l}\text { Fameniense inferior/ } \\
\text { Fameniense temprano }\end{array}$ \\
\hline $\begin{array}{c}\text { ESPAÑOL } \\
\text { (HISPANOAMÉRICA) }\end{array}$ & Fanerozoico & Paleozoico & Devónico & \begin{tabular}{|c|} 
Devónico Superior/ \\
Devónico Tardío
\end{tabular} & Famenniano & \begin{tabular}{|l|} 
Famenniano inferior/ \\
Famenniano temprano \\
\end{tabular} \\
\hline $\begin{array}{c}\text { PORTUGUESS } \\
\text { (PORTUGAL) }\end{array}$ & Fanerozoico & Paleozoico & Devónico & Devónico Superior & Famenniano & Famenniano inferior \\
\hline $\begin{array}{l}\text { PORTUGUES } \\
\text { (BRASIL) }\end{array}$ & Fanerozoico & Paleozoico & Devoniano & $\begin{array}{l}\text { Devoniano Superior/ } \\
\text { Neodevoniano }\end{array}$ & $\begin{array}{l}\text { Fameniano } \\
\text { (OBS.) }\end{array}$ & $\begin{array}{c}\text { Fameniano inferior/ } \\
\text { Eofameniano }\end{array}$ \\
\hline
\end{tabular}

Figura 6. Comparação dos termos em diferentes línguas. Exemplo do Fameniano (Devoniano Superior/ Neodevoniano). OBS.: O termo Fameniano (com um "n") foi adotado a partir da obra de Bosetti et al. (2011), considerada como referência para o Devoniano brasileiro.

dos termos geocronológicos e cronoestratigráficos é importante e necessário, posição esta defendida por vários autores (e.g. Loon 2013, Owen 1987, 2009, Zalasiewicz et al. 2013). O uso inadequado estaria levando a expressões absurdas tanto quanto "outubro inferior" ou "pavimento tardio".

\section{Recomendação final}

O uso distinto de termos cronoestratigráficos e geocronológicos é imperativo, caso se deseje produzir textos geocientíficos rigorosamente dentro da norma. Em se tratando de termos geocronológicos formais do Fanerozoico, os prefixos EO-, MESOe NEO- devem ser utilizados deliberadamente, já que seu uso está previsto no Guia de Nomenclatura Estratigráfica Brasileira (Petri et al. 1986).

\section{Referências}

ABL - Academia Brasileira de Letras 2009. Vocabulário Ortográfico da Língua Portuguesa. Rio de Janeiro: Academia Brasileira de Letras. 877 p. (5 edição).

Arai M. 1991. Teste [sobre termos geocronológicos e cronoestratigráficos]. Boletim da Sociedade Brasileira de Paleontologia - Núcleo RJ/ES, 4 (abril/1991): 9.

Arai M. 1993a. Nomenclatura dos termos geocronológicos informais (Parte 1). Boletim da Sociedade Brasileira de Paleontologia - Núcleo RJ/ES, 23 (agosto/1993): 5.

Arai M. 1993b. Nomenclatura dos termos geocronológicos informais (Parte 2). Boletim da So- ciedade Brasileira de Paleontologia - Núcleo RJ/ES, 24 (setembro-novembro/1993): 4.

Arai M. 1994. Nomenclatura dos termos geocronológicos informais (Parte 3). Boletim da Sociedade Brasileira de Paleontologia - Núcleo RJ/ES, 29 (julhosetembro/1994): 4.

Barreda V., Palamarczuk S. 2000. Estudio palinoestratigráfico del Oligoceno tardío-Mioceno em secciones de la costa patagónica y plataforma continental argentina. In: Aceñolaza F.G., Herbst R. eds. El Neógeno de Argentina. Tucumán: INSUGEO. p. 103-138.

Beurlen G., Richter A.J., Cunha A.S., Silva-Telles Jr. A., Martinis E., Pedrão E., Moura J.A., Gomide J., Viviers M.C., Arai M., Uesugui N., Nascimento N.L., Azevedo R.L., Dino R., Antunes R., Shimabukuro S., Abreu W.S. 1992. Bioestratigrafia das bacias mesozóicas-cenozóicas brasileiras: texto explicativo das cartas bioestratigráficas - Versão 01.88. Rio de Janeiro: PETROBRÁS/ CENPES/ DIVEX/ SEBIPE. 616 p. (Rel. interno).

Bosetti E.P., Grahn Y., Melo J.H.G. (org.) 2011. Ensaios em Homenagem a Frederico Waldemar Lange. Rio de Janeiro: Editora Interciência. 184 p.

Branco P.M. 2014. Guia de redação para a área de Geociências. 2 ed. rev. atualiz. ampl. São Paulo: Oficina de Textos. $224 \mathrm{p}$.

Busca Escolar. 2015. A Pré-História. URL: http://www. buscaescolar.com/historia-geral/a-pre-historia/. Acesso: 12.12.2017.

Carvalho I.S. 2004 (ed.). Coluna Estratigráfica Internacional (UNESCO, 2000). Encarte do volume 2 do livro Paleontologia, $2^{\text {a }}$ edição. Rio de Janeiro: Editora Interciência. 258 p. 
Di Pasquo M. 2003. Avances sobre palinología, bioestratigrafía y correlación de los Grupos Macharetí y Mandiyutí, Neopaleozoico de la Cuenca Tarija, província de Salta, Argentina. Ameghiniana, 40(1): 3-32.

Elsevier. 2017. Cretaceous Research - Author information pack. URL: https:/www.elsevier.com/journals/ cretaceous-research/0195-6671/guide-for-authors. Acesso: 05.12.2017.

Ferreira A.B.H. 1986. Novo dicionário da língua portuguesa. $2^{\mathrm{a}}$ ed. Rio de Janeiro: Nova Fronteira. 1838 p.

Folha de S. Paulo. 1992. Novo Manual da Redação. São Paulo: Folha de S. Paulo. 332 p.

Head M.J., Gibbard P., Salvador A. 2008. The Tertiary: a proposal for its formal definition. Episodes, 31(2):248-250.

Head M.J., Aubry M.-P., Walker M., Miller K.G., Pratt B.R. 2017. A case for formalizing subseries (subepochs) of the Cenozoic Era. Episodes, 40(1):22-27.

Hedberg H.D. 1979. Guide stratigraphique international: classification, terminologie et règles de procédures. Paris: Doin Éditeurs. 233 p. (edição francesa traduzida por Burollet P. et al.)

Hedberg H.D. 1980. Guía estratigráfica internacional. Guia para la clasificación, terminología y procedimentos estratigráficos. Barcelona: Editorial Reverté S/A. 205 p. (edição espanhola traduzida por Petzall C. et al.).

ICS - International Commission on Stratigraphy. 2017. International Chronostratigraphic Chart v. 2017/02. URL: http://www.stratigraphy.org/ ICSchart/ChronostratChart2017-02.pdf. Acesso: 07/12/2017.

ICS - International Commission on Stratigraphy. 2013. Tabela Cronoestratigráfica Internacional v. 2013/01. URL: http://www.stratigraphy.org/ICSchart/ ChronostratChart2013-01Portuguese PT.pdf. Acesso: 24/01/2018.

Knoploch F. 1987. Orientações ortográficas. PETROBRÁS/ CENPES. 2 p. (documento interno).

Kumpulainen R.A. 2017. Guide for geological nomenclature in Sweden. GFF, 139(1): 3-20. URL: http://resource.sgu.se/dokument/om-geologi/ guide-for-geological-nomenclature-in-sweden. pdf. ou http://dx.doi.org/10.1080/11035897.2016. 1178666. Acesso: 05.12.2017.
Loon A.J.(Tom) van. 2013. Stratigraphic Nomenclature. In: Smart P., Maisonneuve H., Polderman A. eds. Science Editors' Handbook. European Association of Science Editors. URL: http://www. ease.org.uk/wp-content/uploads/2-11.pdf. Acesso: 08/12/2017.

MEC - Ministério da Educação. 1990. Acordo Ortográfico da Lingua Portuguesa. URL: http://portal.mec.gov. br/arquivos/pdf/acordoortografico.pdf. Acesso: 23/01/2018.

Owen D.E. 1987. Commentary: usage of stratigraphic terminology in papers, illustrations, and talks. Journal of Sedimentary Petrology, 57(2): 363-372.

Owen D.E. 2009. How to use stratigraphic terminology in papers, illustrations, and talks. Stratigraphy, 6(2): 106-116.

Petri S., Coimbra A.M., Amaral G., Ponçano W.L. 1986. Guia de nomenclatura estratigráfica. Revista Brasileira de Geociências, 16(4): 376-415.

Quattrocchio M.E., Martínez M.A., García V.M., Zavala C.A. 2003. Palinoestratigrafía del Tithoniano-Hauteriviano del centro-oeste de la Cuenca Neuquina, Argentina. Revista Española de Micropaleontología, 35(1): 51-74.

Rios-Netto A.M., Koutsoukos E.A.M. 1994a. Usage of prefixes Eo, Meso and Neo in stratigraphic nomenclature. Anais Acad. Bras. Ciências, 66(2): 256.

Rios-Netto A.M., Koutsoukos E.A.M. 1994b. Utilização dos prefixos Eo, Meso e Neo, em nomenclatura estratigráfica. Anais Acad. Bras. Ciências (minuta com 3 páginas).

Silva J.P. 2017. Manual de Ortografia da Lingua Portuguesa. URL: www.gpesd.com.br/baixar.php?file $=4$. Acesso: 05.12.2017.

Tufano D. 2008. Guia Prático da Nova Ortografia. São Paulo: Editora Melhoramentos Ltda. 32p. URL: https://www.escrevendoofuturo.org.br/EscrevendoFuturo/arquivos/188/Guia_Reforma_Ortografica_CP.pdf. Acesso: 07.12.2017.

Wikipedia. 2017. Paleolítico. URL: https://pt.wikipedia. org/wiki/Paleol\%C3\%ADtico. Acesso: 12.12.2017.

Zalasiewicz J., Cita M.B., Hilgen F., Pratt B.R., Strasser A., Thierry J., Weissert H. Chronostratigraphy and geochronology: a proposed realignment. GSA Today, 23(3): 4-8. 


\section{Apêndice - TESTE}

O teste é de múltipla escolha e só tem uma alternativa correta. Foi publicado originalmente no Boletim da Sociedade Brasileira de Paleontologia - Núcleo RJ/ES (Arai 1991) e é republicado aqui com algumas modificações.

1. Aquele arenito depositou-se no ........

a) Triássico Superior.

b) Neotriássico.

c) Tanto faz.

d) Nenhuma das anteriores.

2. Este poço atingiu o......... a profundidade de $1800 \mathrm{~m}$.
a) Cretáceo Inferior.
b) Eocretáceo.
c) Tanto faz.
d) Nenhuma das anteriores.

3. Esse dinossauro viveu durante o $\ldots . \ldots \ldots$.

a) Jurássico Superior.

b) Neojurássico.

c) Tanto faz.

d) Nenhuma das anteriores.

4. Aquele "bichinho" (fóssil) é do .........

a) Devoniano Médio.

b) Mesodevoniano.

c) Tanto faz.

d) Nenhuma das anteriores.

5. Esse evento vulcânico ocorreu no

a) Terciário Inferior.

b) Eoterciário.

c) Tanto faz.

d) Nenhuma das anteriores.

6. Aquele fóssil provém do .........

a) Ordoviciano Superior.

b) Neo-Ordoviciano.

c) Tanto faz.

d) Nenhuma das anteriores.
7. O trabalho foi intitulado "Registro de novas ocorrências de fósseis vegetais da Formação Santana (....... da Bacia do Araripe)".
a) Cretáceo Inferior.
b) Eocretáceo.
c) Tanto faz.
d) Nenhuma das anteriores.

8. A Formação São Carlos foi datada como . . .......
a) Santoniano superior.
b) Neossantoniano.
c) Tanto faz.
d) Nenhuma das anteriores.

9. Os folhelhos negros da Formação São Carlos depositaram-se no.........
a) Santoniano superior.
b) Neossantoniano.
c) Tanto faz.
d) Nenhuma das anteriores.

10. Aquele mapa representa a reconstituição do Gondwana no..........
a) Triássico Inferior.
b) Eotriássico.
c) Tanto faz.
d) Nenhuma das anteriores.

\section{AVALIAÇÃO:}

Se você acertou todas as dez questões, parabéns. Pode sair por aí ensinando, que você é mestre no assunto.

Se você acertou 7 a 9, não está mal, mas deve tomar muito cuidado ao escrever seu trabalho.

Se você acertou 6 ou menos, a situação é crítica. Você deve se inteirar das regras antes de fazer o uso dos termos geocronológicos e cronoestratigráficos.

\section{GABARITO:}

1 - b; 2 - a; 3 - b; 4 - c; 5 - d (o certo é Paleógeno); 6 - a; 7 - a; 8 - a; 9 - b; 10 - b. 